\title{
Synthetic Phosphoethanolamine Induces Apoptosis Through Caspase-3 Pathway by Decreasing Expression of Bax/Bad Protein and Changes Cell Cycle in Melanoma
}

Adilson Kleber Ferreira1, Renato Meneguelo², Salvador Claro Neto², Gilberto Orivaldo Chierice ${ }^{2}$ and Durvanei Augusto Maria*

${ }^{1}$ Biochemistry and Biophysical Laboratory, Butantan Institute, Av. Vital Brasil, 1500, Sao Paulo, Brazil

${ }^{2}$ Department of Chemistry and Technology of Polymers of the University Sao Paulo - Sao Carlos, Brazil

\section{Summary}

Phospholipids are potential antineoplastic agents that are abundant constituents of the cell membrane of eukaryotes and are supposed to be involved in specific intracellular signaling such as cell death. The aim of this study was to assess the in vitro and in vivo antitumor effects of synthetic phosphoethalomanine (PHO-S) on B16F10 murine melanoma cells and normal human fibroblasts. The cytotoxicty was evaluated by MTT assay and PHO-S was cytotoxic in melanoma cells but not in fibroblasts with IC $50 \%$ of $1.4 \mathrm{mg} / \mathrm{ml}$ to melanoma cells. In vivo antitumor activity was evaluated in a mice model subcutaneously injected with B16F10 melanoma cells. The mice treated with PHO-S in all concentrations showed a decrease of the tumor growth and metastasis. Cytometry analysis showed that the PHO-S blocked DNA synthesis, decreased number of melanoma cells in S phase and G2/M, besides increasing number of apoptotic cells, inducing caspase-3 activity and decreasing Bad/Bax protein expression. Histologically, the dorsal tumors in the control group showed pigmented nodular masses with high vascularization and pleomorphic tumor cells. In the treated group, PHO-S reduction vascularization intratumoral with increased of collagen fibers and infiltrates neutrophils. The data indicate that PHO-S is a lipid compound potential with proapoptotic and antiproliferative effects but further work will be necessary to elucidate the antitumor mechanisms.

Keywords: Phoshoethanolamine; Melanoma; Apoptosis; Cell cycle; Caspase-3; Metastasis; Antiproliferative; Bax; Bad

Abbreviations: PHO-S: Synthetic Phosphoethalomanine; PC: Phosphatidylcholine; PE phosphatidylethanolamine

\section{Introduction}

The incidence of melanoma has been steadily increasing over the last three decades, and the discovery of better anti-cancer agents against melanoma is greatly needed. New anticancer agents need to be developed due to an inadequate biodistribution of therapeutic concentrations of chemotherapeutic agents against the tumor, as well as mutations suffered by the tumor cells resulting in molecular changes rendering cancer cells which are resistant to treatments [1,2]. These and many other factors such as reduction of therapeutic activity due to acidic microenvironment associated with hypoxia and the damage caused by the current chemotherapeutic therapies in normal cells are problems faced by patients during treatment, which drive the search for compounds, as well as therapeutic strategies for treating cancer [3].

Phospholipids are present in tissues and there is a special scientific interest in the elucidating of their role in the treatment of cancer. Tumor progression and accompanied adaptive metabolic changes as observed in breast cancers showed high levels of phosphatidylcoline (PC) and phosphatidylethanolamine (PE) in comparison with normal breast tissue [4]. The consistent ratios by which tumor cells alter the lipid metabolism are still unknown, but the metabolism of neoplastic cells has been the target for the development of new anticancer strategies. A class of potential synthetic antineoplastic phospholipids such as alkylphospholipids, collectively termed as "ether lipids" represents promising treatment for cancers. Ether lipids have been shown to be able to reduce the synthesis of PC in cancer cells interfering with turnover of phospholipids induced apoptosis. New lipid compounds and analogs to the ether lipids are currently being developed and tested clinical, one of which is Miltefosine (hexadecylphosphocholine), used for control of cutaneous metastases of human malignant melanoma [5,6]. In a recent study, phospholipids exogenous PE affected HepG2 cell growth through apoptosis and down-regulation of $\mathrm{Bcl}-2$, up regulation of $\mathrm{Bax}$ and increased caspase-3 levels $[7,8]$

In this study, we have evaluated the antitumor activity of synthetic phosphoethanolamine (PHO-S), an amino-ethyl phosphoric ester which was previously synthesized by our group. Therefore, the effects of PHO-S was evaluated using B16F10 mealnoma cells as a model for cellular cytoxicity and in vivo using animals induced with dorsal melanoma tumors.

\section{Materials and Methods}

\section{Chemical}

Amino-ethyl phosphoric ester was prepared according to [9] with purity over $99 \%$ analyzed by High-performance liquid chromatography (HPLC). The stock solution $1 \mathrm{M}$ was dissolved in water and stored at room temperature for in vitro and in vivo test.

\section{Cell culture}

B16F10 murine melanoma (CLR 6475) and human fibroblast (CCL-75) cell lines were obtained from the American Type Culture Collection (ATCC). B16F10 cells and fibroblasts were grown in RPMI-

*Corresponding author: Durvanei Augusto Maria, $\mathrm{PhD}$, Biochemistry and Biophysical Laboratories, Butantan Institute, Sao Paulo, Brasil, cep 05503-900, Tel: 55-11-37267222 (extension 2364); Fax: 55-11- 37261505; E-mail: durvanei@usp.br

Received November 26, 2010; Accepted January 25, 2011; Published February 05, 2011

Citation: Ferreira AK, Meneguelo R, Neto SC, Chierice GO, Maria DA (2011) Synthetic Phosphoethanolamine Induces Apoptosis Through Caspase-3 Pathway by Decreasing Expression of Bax/Bad Protein and Changes Cell Cycle in Melanoma. J Cancer Sci Ther 3: 053-059. doi:10.4172/1948-5956.1000058

Copyright: (c) 2011 Ferreira AK, et al. This is an open-access article distributed under the terms of the Creative Commons Attribution License, which permits unrestricted use, distribution, and reproduction in any medium, provided the original author and source are credited. 
Citation: Ferreira AK, Meneguelo R, Neto SC, Chierice GO, Maria DA (2011) Synthetic Phosphoethanolamine Induces Apoptosis Through Caspase-3 Pathway by Decreasing Expression of Bax/Bad Protein and Changes Cell Cycle in Melanoma. J Cancer Sci Ther 3: $053-059$. doi:10.4172/1948-5956.1000058

1640 medium, supplemented with $10 \%$ inactivated fetal bovine serum, $2 \mathrm{mM}$ L-glutamine, $100 \mathrm{U} / \mathrm{ml}$ penicillin and $100 \mu \mathrm{g} / \mathrm{ml}$ streptomycin and incubated at $37^{\circ} \mathrm{C}$ in a humidified atmosphere containing $5 \% \mathrm{CO}_{2}$.

\section{Cytotoxicity assay}

B16F10 cells and fibroblasts were harvested in exponential phase and seeded in 96-well flat bottom tissue culture plates at a concentration of $1 \times 10^{5}$ cells/100 $\mu \mathrm{l} /$ well. The cells were allowed to grow for $24 \mathrm{~h}$, and treated with concentrations of PHO-S ranging from 0.005 to $6 \mathrm{mg} / \mathrm{ml}$, in six replicates. The cells were then washed with PBS and allowed to grow in complete medium for $24 \mathrm{~h}$. The cell viability was determined by the MTT (3-[4,5 dimethylthiazol-2-yl]-2,5diphenyltetrazolium bromide) colorimetric assay. Briefly, $20 \mu \mathrm{l}$ of MTT reagent (SigmaAldrich, St. Louis, USA) were added to each well at a final concentration of $5 \mathrm{mg} / \mathrm{ml}$, incubated for $4 \mathrm{~h}$ at $37^{\circ} \mathrm{C}$ and centrifuged at $2000 \mathrm{rpm}$ for $10 \mathrm{~min}$. The medium was discarded and $100 \mu \mathrm{l}$ of dimethyl sulfoxide were added to each well. The optical density was measured in a plate reader (Thermoplate TP Reader, Tokay Hit, Japan) at $540 \mathrm{~nm}$. The $50 \%$ inhibitory concentration (IC50) of PHO-S was determined from the dose-effect curve.

\section{Animal studies and treatment regimen}

Thirty female Balb-c mice, six to 8 weeks old, weighting approximately $25 \mathrm{~g}$, were maintained in Butantan Institute of animal care, and given water and feed ration ad libitum. The animals were divided into four treatment groups: $7 \mathrm{mg} / \mathrm{Kg}$ PHO-S, $14 \mathrm{mg} / \mathrm{Kg}$ PHO-S, $7 \mathrm{mg} / \mathrm{Kg}$ Taxol and saline control, and were followed for 50 days. All animal experiments were conducted under a protocol in agreement with ethical principles in animal research, and approved by the ethics committee for animal research of Butantan Institute (process number $566 / 09)$.

\section{Inoculation of mice with B16F10 melanoma cells}

The B16F10 variant of B16 murine melanoma cells were cultured in RPMI-1640 medium supplemented with 10\% FBS, 2 mM L-glutamine, $1 \mathrm{mM}$ sodium pyruvate and $100 \mathrm{U} / \mathrm{ml}$ penicillin and $100 \mu \mathrm{g} / \mathrm{ml}$ streptomycin. Adherent cells were detached from plates with $0.1 \%$ trypsin and $0.2 \%$ EDTA. After trypsin inactivation with 10\% FBS, viable cells were counted based on trypan blue dye exclusion method. For the in vivo experiments $5 \times 10^{4}$ cells suspended in $100 \mu \mathrm{l}$ of PBS were injected subcutaneous (s.c) in the flanks of mice. Ten days after inoculation, the tumors became macroscopically apparent.

\section{Antitumor activity}

Mice were inoculated with B16F10 melanoma cells as described above. Treatments were started on day 10 , when the tumor implanted in the animals reached a volume of $60-100 \mathrm{~mm}^{3}$. The mice were randomly allocated to groups of ten animals, each group was injected intraperitoneally (i.p.) with one of the following preparations: PHO-S $7 \mathrm{mg} / \mathrm{Kg}$, PHO-S $14 \mathrm{mg} / \mathrm{Kg}$ and Taxol $7 \mathrm{mg} / \mathrm{Kg}$ and saline for the control group. The tumor sizes were measured three times a week using a caliper-like instrument during the experiment, and converted to tumor weight by the equation: tumor weight $=\left(\right.$ length $^{2} \times$ width $) / 2$. The experiment was ended on day 50 , but the survival of the animals in each experimental group was monitored over 180 days.

\section{Determination of tumor growth in mice}

Animals were s.c inoculated with $5 \times 10^{4} \mathrm{~B} 16 \mathrm{~F} 10$ cells (day zero). The tumor volume was estimated on alternate days, from two-dimensional tumor measurements performed with a slide caliper following the above-mentioned formula. Tumor volume of the treated group was compared with that of the control group and the results were expressed as $\mathrm{T} / \mathrm{C}$, where $\mathrm{T} / \mathrm{C} \%=($ tumor mean in treated group/tumor mean in control group) $\mathrm{X} 100$.

\section{Flow cytometric DNA analysis}

B16F10 tumor cells were treated with $1.6 \mathrm{mg} / \mathrm{ml} \mathrm{mg}$ and $3.3 \mathrm{mg} /$ $\mathrm{ml}$ PHO-S and were harvested, washed with PBS and resuspended in $300 \mu \mathrm{l} 0.03 \mathrm{~g} / \mathrm{l}$ trypsin, $10 \mathrm{mM}$ Tris ( $\mathrm{pH} 8.0$ ). After $15 \mathrm{~min}$ incubation at room temperature, $100 \mathrm{ul}$ of the neutralization solution $(0.5 \mathrm{~g} / \mathrm{l}$ trypsin inhibitor, $0.1 \mathrm{~g} / \mathrm{l}$ RNase A and $1.2 \mathrm{~g} / \mathrm{l}$ spermine) was added and incubation continued for $15 \mathrm{~min}$. After centrifugation cells were resuspended in $300 \mu \mathrm{PBS}$ and fixed by the addition of ice-cold ethanol $70 \%$. Prior to analysis, cells were incubated with $1.8 \mu \mathrm{g} / \mathrm{ml}$ propidium iodide solution (Sigma, St. Louis, MO) and incubated in the dark for $30 \mathrm{~min}$. Flow cytometric analysis was performed using a FACScan flow cytometry system (Becton Dickinson, San Jose, CA). The DNA content in the cell cycle phases (G0/G1, S and G2/M) was analyzed by the CellQuest software and by the ModFit LT software (Becton, Dickinson, NJ, USA).

\section{Obtaining the tumors cells of mice with B16F10 dorsal melanoma}

Tumors B16F10 treated with PHO-S and control groups were aseptically removed and placed in cold Hanks' balanced salt solution with 50 units $/ \mathrm{ml}$ heparin, necrotic tissues were excised and remaining tumor was minced by using a scalpel. The explant was washed in phosphate buffer saline, dissociation of $0.5 \mathrm{~g}$ minced tissue was performed in a cold enzyme cocktail of $5 \mathrm{mg}$ collagenase type II, 5 mg collagenase type IV, $10 \mathrm{mg}$ DNase, $5 \mathrm{ml}$ RPMI-1640 for $45 \mathrm{~min}$ of constant mixing. The tumor cells suspension was passed through gauze, Hanks' balanced salt solution washed, then washed with PBS without $\mathrm{Ca}^{++}$or $\mathrm{Mg}^{++}$. Tumor cells were suspended in FACS buffer (BD) at $10^{5}$ cells $/ \mathrm{ml}$, and labeled with a 1:100 dilution monoclonal antibody to mice CD31 (is expressed constitutively on the surface of adult and embryonic endothelial cells and is weakly expressed on many peripheral leukocytes and platelets), CD34 (expressed on the surface of lymphohematopoietic stem and progenitor cells, smallvessel endothelial cells, embryonic fibroblasts and some cells in fetal and adult nervous tissue), and anti-CD3 (molecules known as the T cell receptor and generate an activation signal in T lymphocytes), were utilized negative control to characterization cell tumor population in flow cytometric analysis. B16F10 tumor cells used were negative for markers CD31, CD34 and anti-CD3.

\section{Assessment of apoptosis by caspase- 3}

Caspase- 3 activity was determined by flow cytometry in cells obtained from dorsal tumors of the groups treated with 7 and $14 \mathrm{mg} /$ Kg PHO-S and control using NucView assay. NucView ${ }^{\text {rm }} 488$ Caspase-3 substrate (Biotium Inc., USA) is a cell membrane-permeable caspase substrate designed for detecting caspase- 3 activity within live cells. The substrate is cleaved by caspase- 3 in the cytoplasm of apoptotic cells, releasing a fluorescent DNA dye that is able to enter the nucleus and stain the DNA. Briefly, $200 \mu \mathrm{l}$ of cell suspension were transferred to a flow cytometry tube. Two microliters of NucView ${ }^{\text {mix }} 488$ caspase-3 substrate were added to the cells with or without Z-VAD-FMK, nonspecific fluorescent control (isotype) for pancaspase inhibitors followed by incubation at room temperature in the dark for $15 \mathrm{~min}$. The cells were analyzed using flow cytometry FACScan flow cytometer (Becton Dickinson and Co.) and from dot plots of events recorded in the FL2 channel.

\section{Detection of apoptosis by Annexin V/PI double-staining in flow cytometry}

The Annexin V-FITC/PI apoptosis detection kit (BD'Bioscience) was used to detect the effects of PHO-S after treatment of the animal and 
Citation: Ferreira AK, Meneguelo R, Neto SC, Chierice GO, Maria DA (2011) Synthetic Phosphoethanolamine Induces Apoptosis Through Caspase-3 Pathway by Decreasing Expression of Bax/Bad Protein and Changes Cell Cycle in Melanoma. J Cancer Sci Ther 3: $053-059$. doi:10.4172/1948-5956.1000058

control. B16F10 cells were collected from dorsal tumor as previously described and centrifuged for $15 \mathrm{~min}$. The pellet was suspended with $1 \times$ binding buffer $(100 \mu \mathrm{l})$. The cells were stained with Annexin V $(5$ $\mu \mathrm{l})$ and PI $(5 \mu \mathrm{l})$, and incubated for $15 \mathrm{~min}$ at room temperature in the dark. After incubation, cells received $400 \mu 1 \times$ binding buffer and then were analyzed by flow citometry FACScan (Becton Dickinson and Co.) using CellQuest Software, which can determine the percentage of apoptotic cells. PI was excited at $488 \mathrm{~nm}$, and fluorescence was analyzed at $620 \mathrm{~nm}$.

\section{Measurement of Bcl-2, Bax and Bad expression by flow cytometry}

The expression of the ant-apoptotic protein Bcl-2 and proapoptotic proteins Bad/Bax was measured in the cells obtained from dorsal tumors of the groups treated with PHO-S and control. Briefly, $10^{6}$ cells were incubated with $100 \mu \mathrm{l}$ PBS $0.1 \%$ triton X-100 on ice for 30 min. Primary antibody anti-Bcl-2, anti-Bad/Bax (Abcam, UK) was then added, and the cells were incubated on ice for $30 \mathrm{~min}$. The cells were washed twice with PBS, and incubated on ice with secondary antibody Alexa Fluor ${ }^{\circledR} 647$ (Invitrogen CA, USA) for $30 \mathrm{~min}$. The cells were centrifuged, washed and the cells were ressuspended in $300 \mu \mathrm{l}$ PBS. The flow cytometry analysis was performed using a FACScan system (Becton-Dickinson, San Jose, CA).

\section{Histological and histochemical analysis}

Tissue specimens were fixed in $10 \%$ buffered formalin and routinely processed for paraffin embedding. Sections of $5 \mu \mathrm{m}$ were obtained and stained with: Hematoxylin-eosin to assess tissue integrity; Van Gieson to differentiate between collagen and smooth muscle and to demonstrate the increase of collagen; and Picrosirius red under polarized light to detect differences in overall connective tissue.

\section{Statistical analysis}

Unpaired Student's T test was used to evaluate cell survival and cell growth. Analysis of Variance (ANOVA) was used to assess the flow cytometry results and the growth tumor inhibition curve. All values were expressed as mean $\pm \mathrm{SD}$. In all analysis, $P<0.05$ was considered statistically significant. The survival time plot (Kaplan-Meier test) and survival comparison between groups were carried out using the Graph Pad Prism statistical software.

\section{Results}

\section{Cytotoxic effects of PHO-S on B16F10 melanoma}

The results showed that PHO-S was cytotoxic against B16F10 cells at concentrations 1.5 to $6 \mathrm{mg} / \mathrm{ml}$ (IC50\% $1.4 \mathrm{mg} / \mathrm{ml}$ ). Normal fibroblasts were not affected (Figure 1). The B16F10 cells showed morphological changes under PHO-S treatment with "blebs" formation, spindle-shape and cell detachment even at non-toxic concentrations as compared to the control cells (Figure 2).

PHO-S inhibits metastasis, increases survival rate and decreases tumor volume

Taxol reduced $60 \%$ the tumor volume compared with control, but the reduction of tumor volume in the mice treated with PHO-S was significantly highly in approximately $86 \%$ as compared with the control and treated with Taxol. The survival rates were significantly increased in the treated groups and no significant weight loss was observed (Figure 3a and Figure 3b). Untreated mice showed increased number of metastasis $98.5 \% \pm 1.2$ in the lung, kidneys, liver and new blood vessels. Treatment with PHO-S $7 \mathrm{mg} / \mathrm{Kg}$ and $14 \mathrm{mg} / \mathrm{Kg}$ resulted in inhibition respectively $5.4 \% \pm 1.7$ and $13 \% \pm 1.8$ showing a greater efficacy in reducing the number of metastases compared to Taxol $34.2 \% \pm 1.7$ (Figure 4a and Figure 4b).

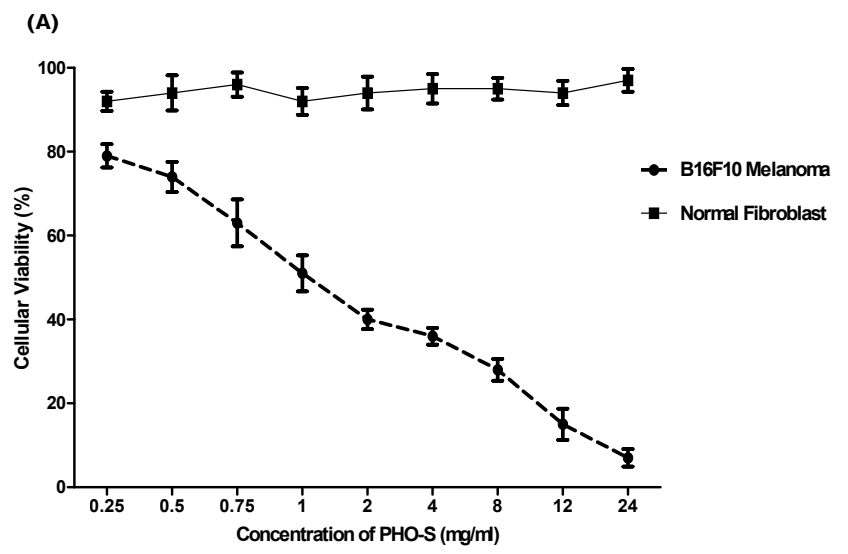

(B)

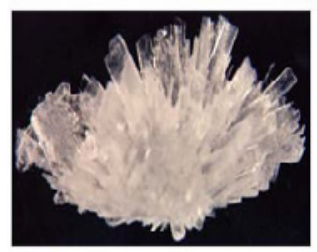

(C)<smiles>NCCOP(=O)(O)O</smiles>

Figure 1: Toxicity induced by PHO-S in B16F10 tumor and fibroblast cells evidenced by MTT colorimetric assay. The dose effect curve shows concentration-dependent toxicity in B16F10 cells treated with PHO-S (IC50\% $1.4 \mathrm{mg} / \mathrm{ml}$ ), PHO-S did not affect normal fibroblasts. Values depict the mean an average $( \pm S D)$ of eight plate's measurements. Results are representative of three independent experiments (A). Crystal and structure molecular of PHO-S (B and C).

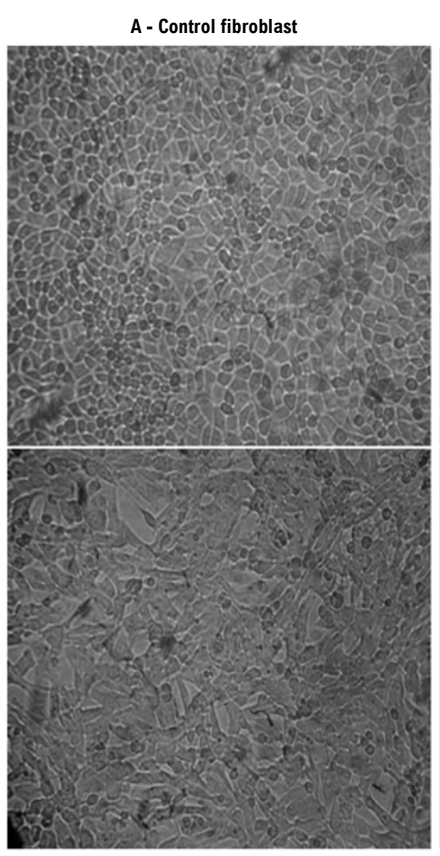

C - Control B16F 10

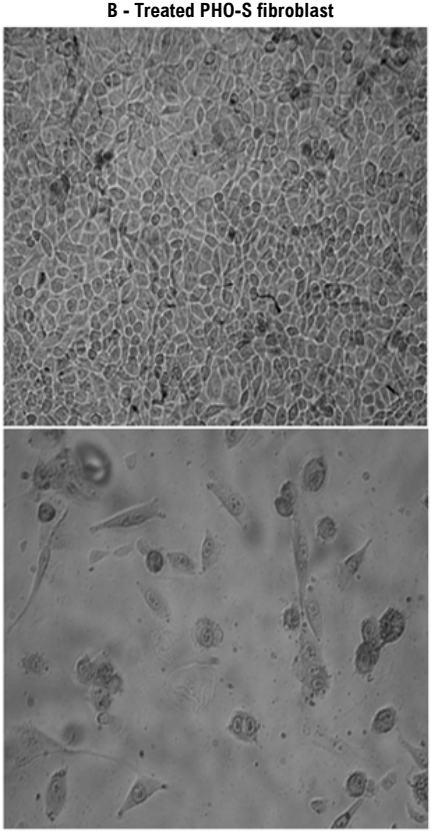

D - Treated PHOS-S B16F10
Figure 2: Photomicrograph image obtained in inverted microscopy of control fibroblast (A) PHO-S treated fibroblast cells (B), control B16F10 melanoma cells (C) changes in the cell morphology as nuclear condensation and cell shrinkage. Similar results were obtained in three independent experiments. Image at 125X magnifications. 
Citation: Ferreira AK, Meneguelo R, Neto SC, Chierice GO, Maria DA (2011) Synthetic Phosphoethanolamine Induces Apoptosis Through Caspase-3 Pathway by Decreasing Expression of Bax/Bad Protein and Changes Cell Cycle in Melanoma. J Cancer Sci Ther 3: $053-059$. doi:10.4172/1948-5956.1000058

PHO-S inhibits melanoma cells proliferation and decreases the number of cells in the $\mathrm{G} 2 / \mathrm{M}$ phase

Tumor cells treated with PHO-S $3.3 \mathrm{mg} / \mathrm{ml}$ reduced their proliferative activity $(P<0.001)$ in $\mathrm{G} 0 / \mathrm{G} 1, \mathrm{~S}$ and $\mathrm{G} 2 / \mathrm{M}$ phases when compared with the control group. The treatment induced apoptosis as detected in a prominent sub-G1 apoptotic peak. The mice group treated with $1.6 \mathrm{mg} / \mathrm{ml}$ PHO-S presented a significant increase $(P<0.001)$ in apoptotic cells and a decrease in cell cycle progression (G0/G1 and $\mathrm{G} 2 / \mathrm{M})$. Quiescent cells significantly decreased $(P<0.001)$ in both concentrations of the treatment (Figure 5a-5c).

The expression of apoptotic and anti-apoptotic proteins were analyzed in tumor cells treated with PHO-S

The relationship of $\mathrm{Bax} / \mathrm{Bcl}-2$ binding was measured to determine whether Bax signaling was a possible mechanism for the PHO-S to induce apoptosis. The treatment with both concentrations unaffected the Bcl-2 expression in the control and PHOS-treated groups. PHO-S $7 \mathrm{mg} / \mathrm{Kg}$ and $14 \mathrm{mg} / \mathrm{Kg}$ induced downregulation of Bax and $\mathrm{Bad}$ protein. Since Bax-Bax dimerization is a prerequisite for mitochondrial translocation of apoptotic proteins such as cytochrome $c$, followed by apoptosis. Suggesting that PHO-S induces apoptosis independent of blockade of Bcl-2 (Figure 6).

(A)

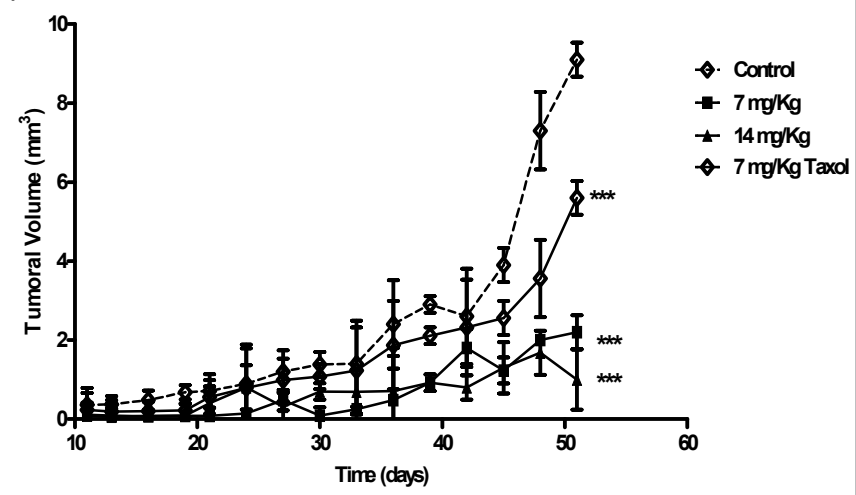

(B)

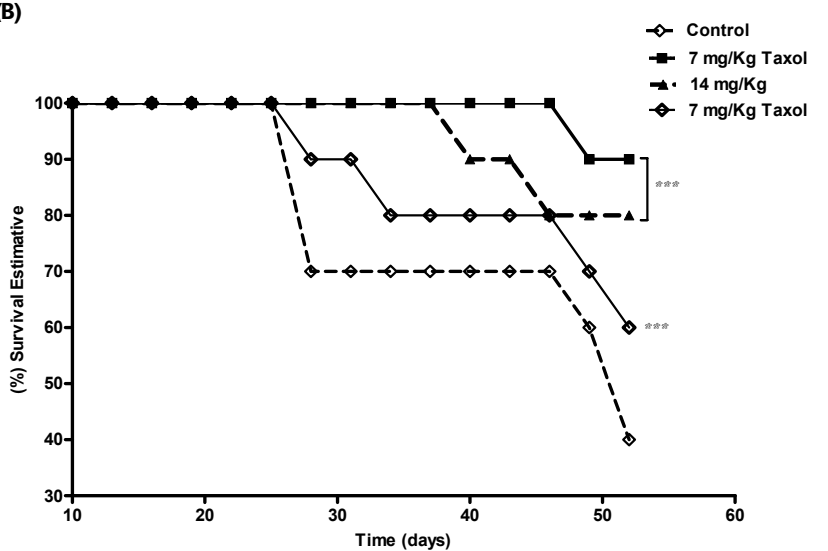

Figure 3: PHO-S treatment started at day 10 after tumor cells injection and was continued every other day until day 50 and measurements of tumor dimensions were estimated on alternate days. PHO-S $7 \mathrm{mg} / \mathrm{Kg}$ and $14 \mathrm{mg} / \mathrm{Kg}$ reduction significantly of tumor volume compared with Taxol $7 \mathrm{mg} / \mathrm{Kg}$ and control group. Kaplan-Meier survival estimates for the cohort of mice treated with PHO-S, as compared with control and Taxol (B). The statistic unpaired t-test showed ${ }^{* * *} \mathrm{P}<0.001$ for all experimental groups treated with $\mathrm{PHO}-\mathrm{S}$ as compared with control and Taxol.
(A)
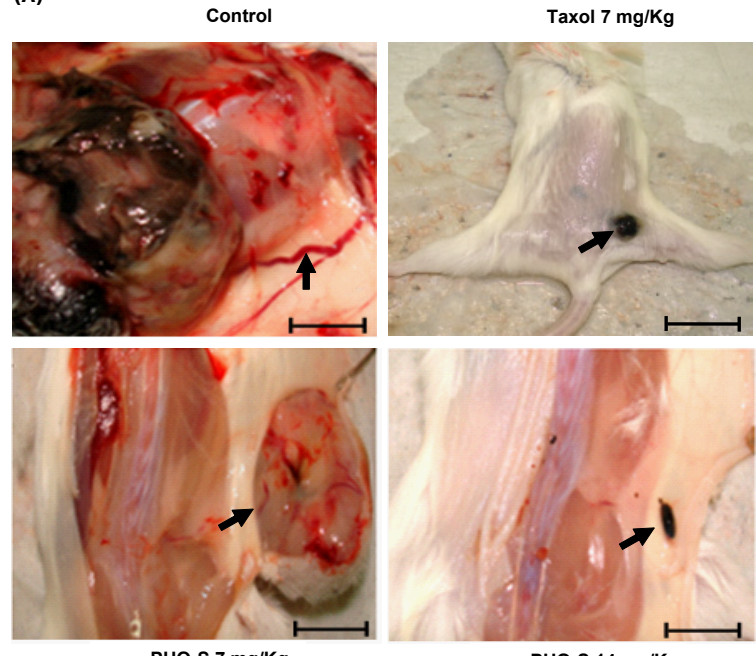

(B)

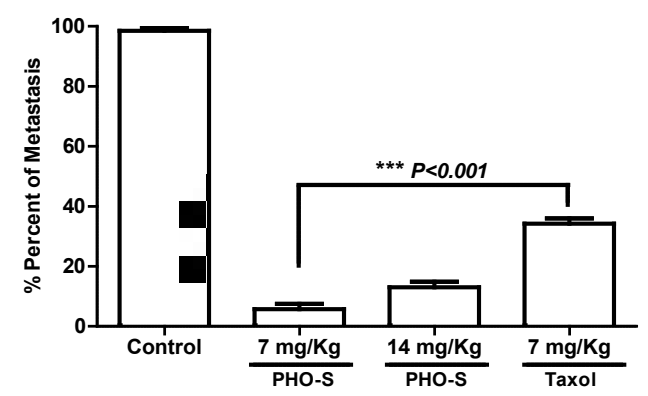

(C)

Control

Control

Taxol

PHO-S
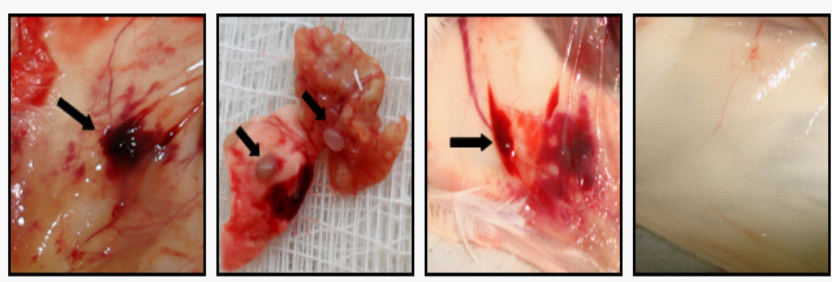

Figure 4: Macroscopic effect of treatment on melanoma growth in mice models. Control showed large tumor with areas hemorrhagic (arrows). PHO-S volume reduced of the dorsal tumor and notice that the tumor is surrounded by a fibrillar capsule (arrows). Mice were maintained alive for 180 days and after the last injection on day 50, the control group was sacrificed and the tumor nodules in internal organs were counted. ${ }^{* * *} P<0.001$ are according to One-Way Analysis of Variance ANOVA. (B and C) Control and treatment with Taxol showed a large area vascularized, metastasis in lung parenchyma and lymph nodes. Notice group that received PHO-S no was observed metastasis in lymph nodes (arrows)

\section{PHO-S induces caspase-dependent apoptosis in B16F10 melanoma}

The control B16F10 cells (2.7\%) showed nonspecific fluorescent, while $17 \%$ were labeled for caspase- 3 . Cells treated with $14 \mathrm{mg} / \mathrm{Kg} \mathrm{PHO}-$ S-induced increasing activity of caspase- 3 with $45 \%$ fluorescent specific showed a statistically significant with $4.7 \%$ fluorescent nonspecific. Flow cytometric analysis revealed caspase- 3 in the tumor-bearing animals group treated with $7 \mathrm{mg} / \mathrm{Kg}$ PHO-S with $4.9 \%$ of the tumor cells population with fluorescent nonspecific and $62 \%$ with specific fluorescent to caspase- 3 active (Figure 7). The cells were stained with two 
Citation: Ferreira AK, Meneguelo R, Neto SC, Chierice GO, Maria DA (2011) Synthetic Phosphoethanolamine Induces Apoptosis Through Caspase-3 Pathway by Decreasing Expression of Bax/Bad Protein and Changes Cell Cycle in Melanoma. J Cancer Sci Ther 3: 053-059. doi:10.4172/1948-5956.1000058

cell markers, annexin $\mathrm{V}$ to measure phosphatidylserine translocation to the extracellular leaflets (early apoptosis) and PI to measure the loss of phospholipid membrane integrity (late apoptosis/necrosis). Treatment

(A)

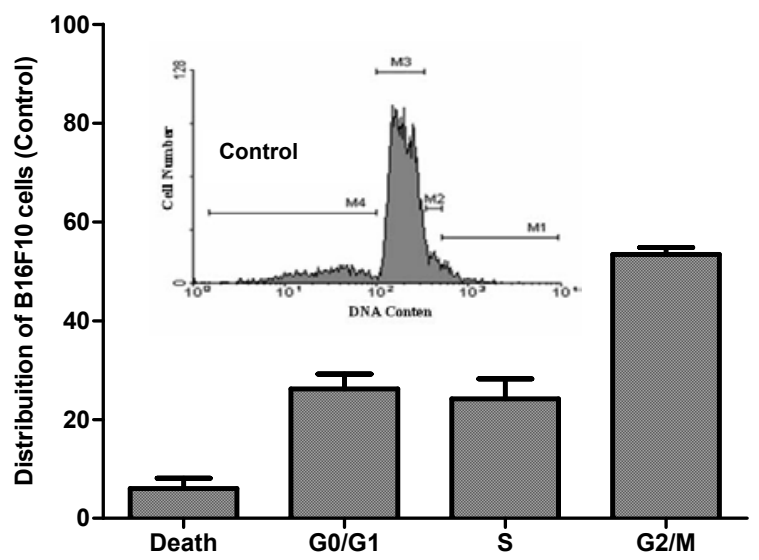

(B)

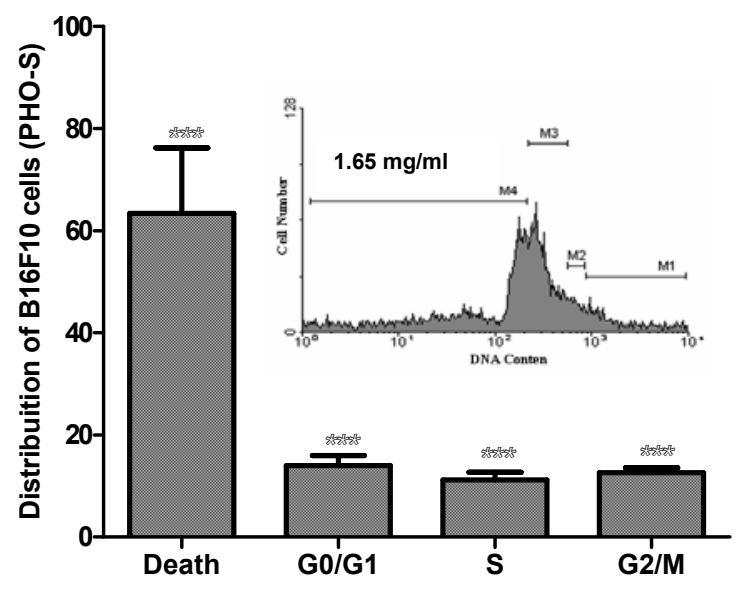

(C)

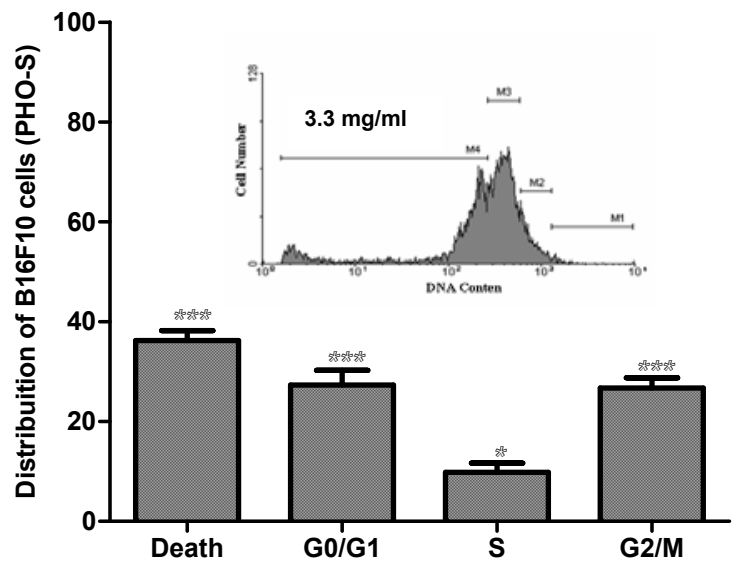

Figure 5: Effects of PHO-S on B16F10 tumor regarding each phase of the cell cycle. Propidium iodide (PI) stained cells were measured using a FACScan flow cytometry. The proportion of cells residing in DNA fragmented (M1), G0/ G1 (M2), S (M3) and G2/M (M4) phases of the cell cycle, are indicated (inset). The control group showed increased number of cells in G2/M and phase S (A). Treatment of B16F10 melanoma with PHO-S reduced number of cells in G2/M and increased the number of dead cells (B and C). Notice PHO-S $1.6 \mathrm{mg} / \mathrm{m}$ was significantly more effective than $3.3 \mathrm{mg} / \mathrm{ml}$ in distribution of cell in the cell cycle phases.

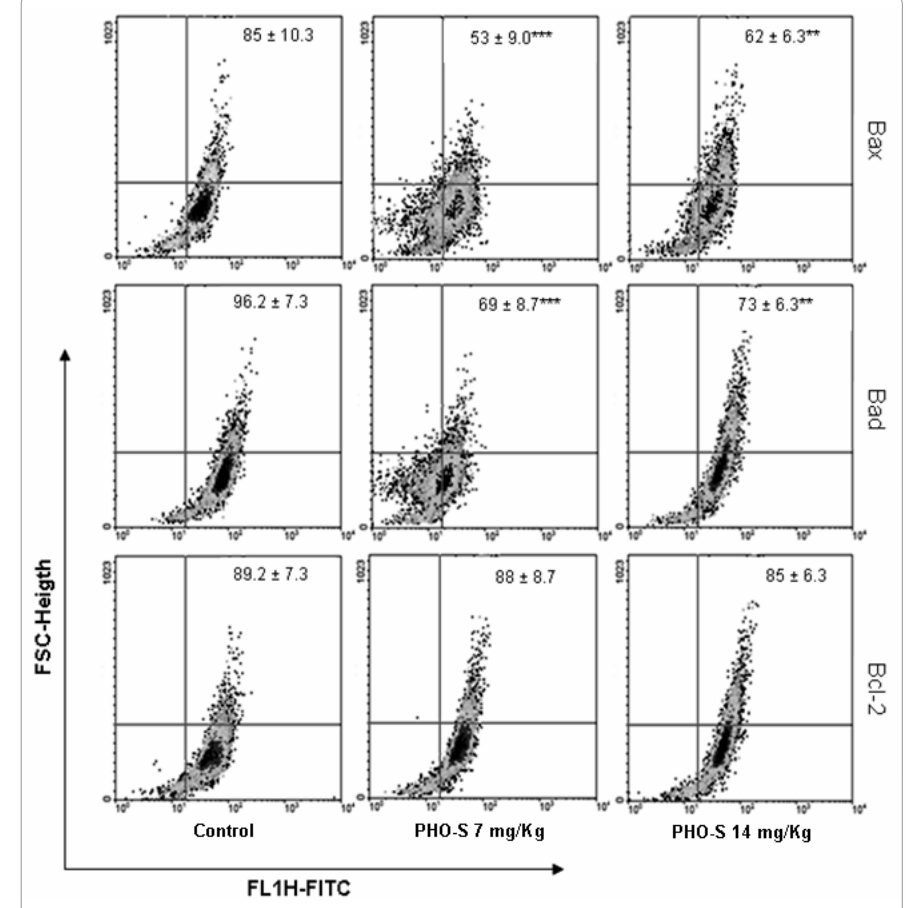

Figure 6: $\mathrm{PHO}-\mathrm{S}$ induced downregulation of Bax/Bad in B16F10 tumor cells PHO-S $7 \mathrm{mg} / \mathrm{Kg}$ and $14 \mathrm{mg} / \mathrm{Kg}$ was able to induce apoptosis, and to decrease protein expression of Bad/Bax $(\mathrm{P}<0.001)$. The levels of $\mathrm{Bcl}-2$ protein were not altered in relation to treated groups (inset). Values depict the mean an average $( \pm S D)$ and are representative of three independent experiments.

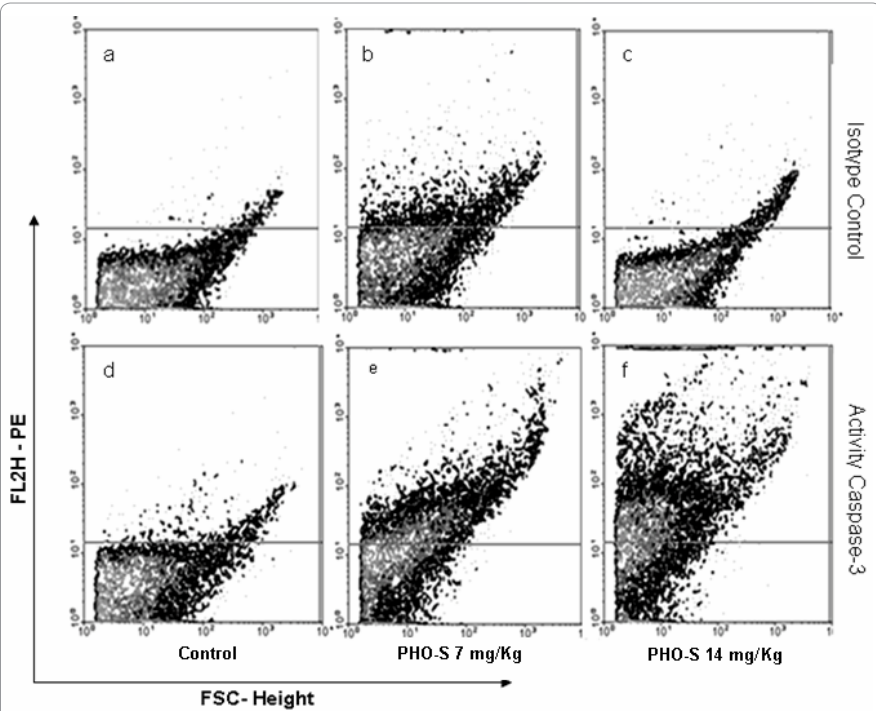

Figure 7: Expression of caspase-3 activity. PHO-S induced apoptosis in B16F10 tumor cells in caspase-3-dependent manner, was measured by flow cytometry. (A, B and C) Z-VAD-FMK nonspecific fluorescent control in B1610 tumor cell. Caspase-3 activity B16F10 tumor cells untreated (D), PHO-S treated B16F10 tumor cells (E and F). The results are representative of three separate experiments. Data are expressed as a dot plot of mean ( $\pm S D)$.

of the B16F10 tumor cells with PHOS-S in all concentrations resulted in $41 \% \pm 2.1$ increase of early apoptotic cells and $8.2 \% \pm 0.8$ increase of late apoptotic/necrotic cells, compared with controls ( $10 \% \pm 1.2$ apoptotic cells, $21 \% \pm 2.6$ necrosis, $7.9 \% \pm 0.9$ early apoptotic cells). These data suggest that $\mathrm{PHO}-\mathrm{S}$ is highly effective in controlling tumor progression by apoptosis (Figure 8). 
Citation: Ferreira AK, Meneguelo R, Neto SC, Chierice GO, Maria DA (2011) Synthetic Phosphoethanolamine Induces Apoptosis Through Caspase-3 Pathway by Decreasing Expression of Bax/Bad Protein and Changes Cell Cycle in Melanoma. J Cancer Sci Ther 3: $053-059$. doi:10.4172/1948-5956.1000058

\section{Histological examination}

The control group showed a higher number of metastasis, enhanced cellular pleomorphism with intracellular and extracellular melanin deposition. Dorsal tumors showed increased mitotic figures, newly formed blood vessels, hemorrhagic areas, and rare intratumoral necrosis without inflammatory infiltration. Treatment with PHO-S at either concentration tested decreased irrigation without metastatic and increased necrotic, fibrotic areas with extensive intra-tumor collagen type I and increased number of infiltration neutrophils (Figure 9).

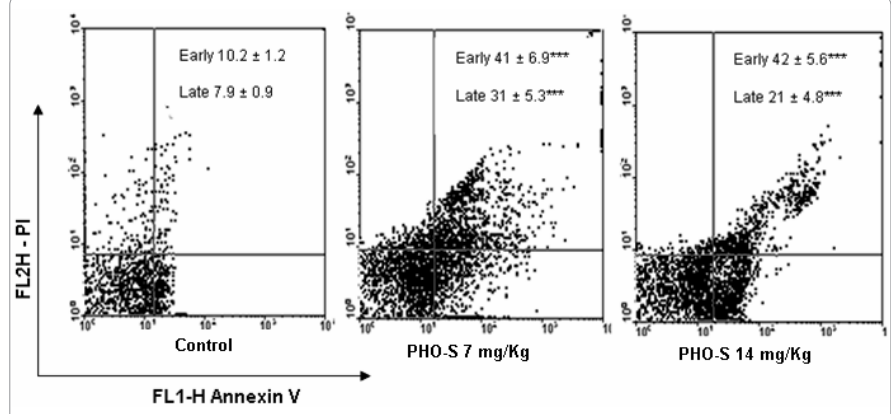

Figure 8: Detection of the apoptotic cells by flow cytometry. Tumors cells from treated animals were stained with annexin V (apoptotic cells) and PI (necrosis). PHO-S induced an increase in the population of apoptotic cell in both concentrations. The results are representative of three separate experiments. Data are expressed as a dot plot of mean $( \pm S D)$.

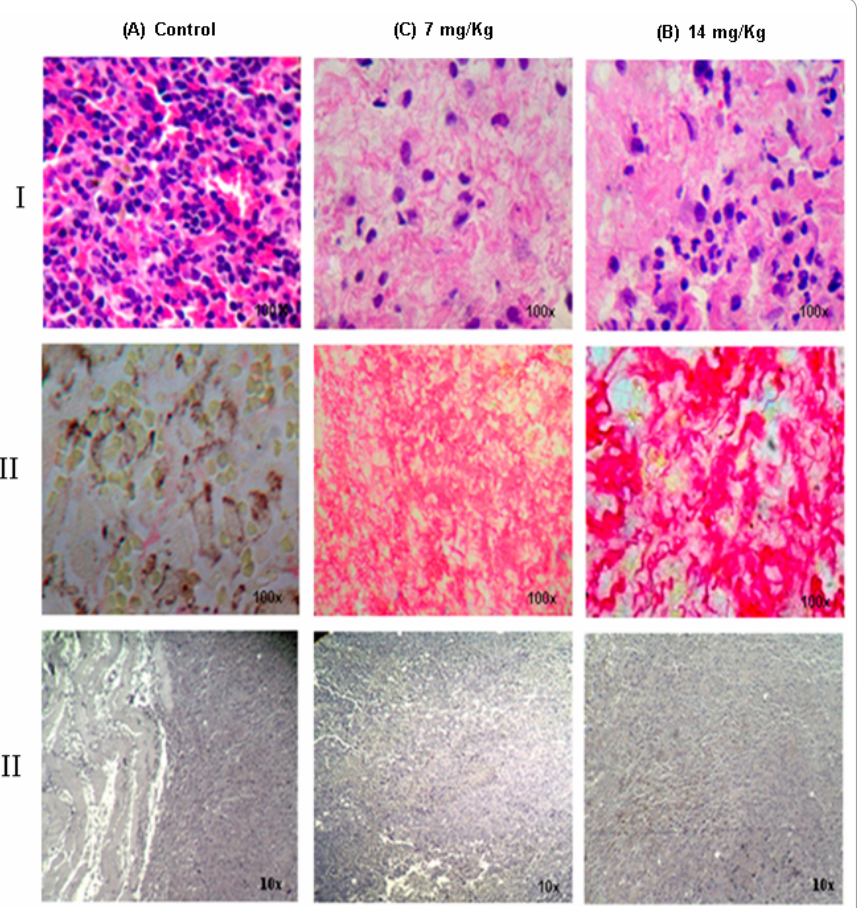

Figure 9: PHO-S inhibition of the melanoma growth in treated mice. Representative photomicrographs of tumor sections stained with hematoxylin eosin. (I) $\mathrm{A}, \mathrm{B}$ and $\mathrm{C}$ PHO-S decreased density of tumor cells the amount of inflammatory cells, the cellular degeneration and fibrosis. The control shows large hemorrhagic areas with numerous tumor cells. (II) A, B and C. Photomicrographs of Sirius Red-stained melanoma tumor sections from treated mice showing a large area of intratumor collagen deposition, not observed in the control. (III) A $B$ and $C$ Verhoeff-van Gieson stain showed that significant decrease of elastic fibers around endothelial cells was observed in the PHO-S treated groups.

\section{Discussion}

Cancer is basically a cell disease, characterized by a loss in the mechanisms which drive the proliferation and cellular differentiation. Melanoma is a kind of cancer which represents about $1 \%$ of all tumors and is responsible for $75 \%$ of skin cancer deaths. The standard treatment for metastatic melanoma and Dacarbazine is currently the only FDAapproved chemotherapy drug for metastatic stage IV melanoma, but its therapeutic response is poor and only $15-20 \%$ of patients with favorable prognosis have increased survival rate [10-12].

The present results showed that PHO-S is cytotoxic and inhibits $\mathrm{B} 16 \mathrm{~F} 10$ cells growth in a concentration-dependent manner (IC50\%=1.4 $\mathrm{mg} / \mathrm{ml}$ ), and revealed no induced citotoxicity and morphologic changes in normal human fibroblasts (CCL-75) indicanting that compound a potential anti-cancer agent which may produce less toxicity to normal cells.

Solid tumors that present relatively slow cellular divisions, such as lung, colon and breast carcinomas, constitute more than $90 \%$ of all the types of human cancer and, for this reason, they are in urgent need for new drugs. In recently released a new guideline for the treatment of metastatic melanoma and Taxol was considered by National Comprehensive Cancer Network (v.1.2009 ME-D) as firstline treatment for melanoma, and is considered highly effective therapy when used in combination with Dacarbazina e IL-2. Based on these new guidelines and the results obtained in this study, the PHO-S was highly effective when compared to Taxol in reducing tumor volume and increased survival rate [13]. Ally the need for developing new drugs for the treatment of malignant tumors such as melanoma the PHO-S is considered as a future agent to combat the malignant tumors. The characteristics of malignant tumors which are the most influent on the development of targets for prognosis of malignant melanoma are aggressiveness multidrug resistance and metastasis remains that an obstacle in cancer therapy [14-16]. Melanoma found to be less than or equal to $1.0 \mathrm{~mm}$ are at a lower risk of nodal involvement. In patients with thin melanomas (depth of less than $1 \mathrm{~mm}$ ), the rate of nodal involvement seemed so low that an elective lymph node dissection was not warranted. For melanomas with depths greater than $4 \mathrm{~mm}$, the risk of systemic metastasis seemed to outweigh the potential benefit of elective lymph node dissection $[17,18]$.

In the in vivo study, B16F10 cells of the control group showed spreading nodules in several organs and macroscopic areas of intense neovascularization. These metastases were preferentially distributed in the lung, liver parenchyma and satellite lymph nodes. The reports on the molecular mechanisms involved in the metastatic process led many investigators to look for experimental therapies directed towards inhibiting or regulating one or subsequent steps of the metastatic cascade [19]. In the present study, PHO-S 7 and $14 \mathrm{mg} / \mathrm{Kg}$ significantly inhibited the number of metastasis compared to Taxol $7 \mathrm{mg} / \mathrm{Kg}$. These results suggest that the compound has antimetastatic activities, but complementary studies are required to determine its action mechanisms.

Many chemotherapeutic agents cause cell-cycle arrest but not apoptosis. Different concentrations of PHO-S significantly increased apoptotic cells, suggesting that it is a selective and specific compound in inducing cell death. Flow cytometry analysis indicates that PHO-S induces an increase in quiescent cell phase proportion, a decrease in DNA synthesis phase and in G2/M cells. Membrane phospholipid degradation is rapid when the cells re-enter G1 phase after quiescence. During G1 phase, both the choline pathway and phospholipasemediated PC hydrolysis are, therefore, at their maximum activity and 
Citation: Ferreira AK, Meneguelo R, Neto SC, Chierice GO, Maria DA (2011) Synthetic Phosphoethanolamine Induces Apoptosis Through Caspase-3 Pathway by Decreasing Expression of Bax/Bad Protein and Changes Cell Cycle in Melanoma. J Cancer Sci Ther 3: $053-059$. doi:10.4172/1948-5956.1000058

are maintained in $S$ phase $[20,21]$. The increased number of cells in G1 suggests that inhibition of cell proliferation and of G1-S phase transition in PHO-S treated B16F10 melanoma is a result of the activation of caspases, the key effector molecule in apoptosis that are potential targets for pharmacological modulation of cell death.

PHO-S treatment of tumor-bearing mice showed a significant increase in the proportion of cells in apoptosis the caspase-3 pathway, and a decrease in $\mathrm{G} 2 / \mathrm{M}$, indicating that the outcome is apoptotic cell death. Considering the general resistance of melanoma cells to apoptosis, these results emphasize the potential of PHO-S as a new agent for the treatment of cancer.

Imbalance of the Bax/Bcl-2 ratio would render tumor cells which are more resistant to a wide variety of cell death stimuli, including all chemotherapeutic drugs [22-24]. In this study we show that potent $\mathrm{PHO}-\mathrm{S}$ induced apoptosis via caspase-3 independent the downregulation of $\mathrm{Bcl}-2$ protein or presence of once $\mathrm{Bax}$ is released from Bcl-2 inducing Bax-Bax oligomerization protein complex follows and inserts in the outer mitochondrial membrane, causing mitochondrial permeabilization and release of the proapoptotic factors AIF, Smac/Diablo, and cytochrome $c$.

Histological analysis of B16F10 melanoma tumors in the control group showed intense spreading of the tumor, which is typical of its aggressiveness $[25,26]$. The tumors of mice treated with PHO-S had predominant infiltration as neutrophils being that entrapped melanoma cells produced and secreted high levels of a cytokine interleukin-8, attracting neutrophils and increasing tethering $\beta 2$ integrin expression cellular adhesion molecule- 1 on melanoma cells and $\beta 2$ integrin on neutrophils interacted, promoting anchoring to endothelium. Transendothelial migration and lung metastasis development decrease in melanoma cells have the potential to decrease metastasis development by disrupting interaction with neutrophils [27]. Histochemical analysis of control group tumors revealed a low density of fibrillar collagen and increase in fenestrated newly formed vessels. In the PHO-S-treated groups, there was intense deposition of collagen type I and pro-collagen fibers around the tumor mass and a decrease in newly formed blood vessels.

In conclusion, $\mathrm{PHO}-\mathrm{S}$ demonstrated high selectivity and specificity against tumor cell proliferation and dissemination triggered through increased apoptosis caspase-3 pathway and downregulation of Bad/Bax. This study adds to a better understanding of PHO-S action mechanisms and provides a potential tool for melanoma treatment.

\section{Acknowledgment}

This study was supported by the Foundation for Research Support of Sao Paulo (FAPESP), Process No. 2007/50571-3.

\section{References}

1. Egeblad M, Nakasone ES, Werb Z (2010) Tumors as organs: complex tissues that interface with the entire organism. Dev Cell 18: 884-901.

2. Mao C, Liao RY, Qiu LX, Wang XW, Ding H, et al. (2010) BRAF V600 mutation and resistance to anti-EGFR monoclonal antibodies in patients with metastatic colorectal cancer: a meta-analysis. Mol Biol Rep.

3. De Milito A, Fais S (2005) Tumor acidity, chemoresistance and proton pump inhibitors. Future Oncol 1: 779-786.

4. Morse DL, Carroll D, Day S, Gray H, Sadarangani P, et al. (2009) Characterization of breast cancers and therapy response by MRS and quantitative gene expression profiling in the choline pathway. NMR Biomed 22: 114-127

5. van der Luit AH, Vink SR, Klarenbeek JB, Perrissoud D, Solary E, et al. (2007)
A new class of anticancer alkylphospholipids uses lipid rafts as membrane gateways to induce apoptosis in lymphoma cells. Mol Cancer Ther 6: 2337 2345.

6. Danker K, Reutter W, Semini G (2010) Glycosidated phospholipids: uncoupling of signalling pathways at the plasma membrane. $\mathrm{Br} \mathrm{J}$ Pharmacol 160: 36-47.

7. Yao Y, Huang C, Zong-Fang Li, Wang Ai-Ying, Li-Ying Liu, et al. (2009) Exogenous phosphatidylethanolamine induces apoptosis of human hepatoma HepG2 cells via the bcl-2/bax pathway. World J Gastroenterol 15: 1751-1758.

8. Hac-Wydro K, Dynarowicz-Łatka P (2010) Effect of edelfosine on tumor and normal cells model membranes--a comparative study. Colloids Surf B Biointerfaces 76: 366-369.

9. Outhouse EL (1936) Amino-ethyl phosphoric ester from tumours. Biochem $J$ 30: $197-201$

10. Luis P, Cashin R, Machado M, Hemels M, Corey-Lisle PK, et al. (2007) Treatments for metastatic melanoma: synthesis of evidence from randomized trials Cancer Treat Rev. 33: 665-680.

11. Mouawad R, Sebert M, Michels J, Bloch J, Spano JP, Khayat D (2010) Treatment for metastatic malignant melanoma: old drugs and new strategies. Crit Rev Oncol Hematol 74: 27-39.

12. Fricker $\mathrm{J}$ (2010) New era in metastatic melanoma. Molecular Oncology 491 497.

13. O'Day S, Gonzalez R, Lawson D, Weber R, Hutchins L, et al. (2009) Phase II, randomized, controlled, double-blinded trial of weekly elesclomol plus paclitaxel versus paclitaxel alone for stage IV metastatic melanoma. J Clin Oncol 10: 5452-5458.

14. Teicher BA (2006) Tumor Models for Efficacy Determination. Molecular Cancer Therapeutics 10: 2435-2443.

15. Burger HM, Abel S, Snijman PW, Swanevelder S, Gelderblom WC (2007) Altered lipid parameters in hepatic subcellular membrane fractions induced by fumonisin B1. Lipids 42: 249-261.

16. Poprach A, Michalová E, Pavlík T, Lakomy R, Vyskocil J, Nemeccek R, Zaloudík J, Vyzula R, Kocák I, Kocáková I (2008) Actual state of ex vivo chemoresistance testing of malignant tumors in Masaryk Memorial Cancer Institute Brno. Klin Onkol 21: 116-121.

17. Crowley, Seigle (1990) The role of elective lymph node dissection in the management of patients with thick cutaneous melanoma. Cancer 66: 25222527.

18. Stadelmann WK (2010) The role of lymphatic mapping and sentinel lymph node biopsy in the staging and treatment of melanoma. Clin Plast Surg 37: 79-99.

19. Easson AM, Rotstein LE, McCready DR (2009) Lymph node assessment in melanoma. J Surg Oncol 99: 176-185.

20. Podo F (1999) Tumour phospholipid metabolism. NMR Biomed 12: 413-439.

21. Zhang XH, Zhao C, Ma ZA (2007) The increase of cell-membranous phosphatidylcholines containing polyunsaturated fatty acid residues induces phosphorylation of p53 through activation of ATR. J Cell Sci 120: 4134-4143.

22. Danial NN (2007) Bcl-2 family proteins: critical checkpoints of apoptotic cell death. Clin Cancer Res 13: 7254- 7263.

23. Marzo I, Brenner C, Zamzami N, Jürgensmeier JM, Susin SA, et al. (1998) Bax and adenine nucleotide translocation cooperate in the mitochondrial control of apoptosis. Science 281: 2027-2031.

24. Igney FH, Krammer PH (2002) Death and anti-death: tumour resistance to apoptosis. Nat Rev Cancer 2: 277-288.

25. Smolle J, Fiebiger M, Hofmann-Wellenhof R, Kerl H (1996) Quantitative morphology of collagen fibers in cutaneous malignant melanoma and melanocytic nevus. Am J Dermatopathol 18: 358-363.

26. Eriksson F, Culp WD, Massey R, Egevad L, Garland D, et al. (2007) Tumo specific phage particles promote tumor regression in a mouse melanoma model. Cancer Immunol Immunother 56: 677-687.

27. Huh SJ, Liang S, Sharma A, Dong C, Robertson GP (2010) Transiently Entrapped Circulating Tumor Cells Interact with Neutrophils to Facilitate Lung Metastasis Development. Cancer Res 70: 6071-6082. 